\title{
Distopía y devastación ecológica en 2010: Chile en llamas (1998) de Darío Oses'
}

\author{
Dystopia and ecological devastation in 2010: \\ Chile en llamas (1998) by Darío Oses
}

Juan Gabriel Araya Grandón

Universidad del Bío-Bío. Chillán, Chile.

jaraya@ubiobio.cl

\section{RESUMEN}

La novela 2010: Chile en llamas (1998) del chileno Darío Oses anuncia un futuro signado por la contaminación de todas las esferas de la sociedad. Calificamos esta narración como distópica, pues se plantea como una utopía negativa que neutraliza los flujos vitales de la Tierra en conexión con el ser humano. Paisajes y territorios geográficos y existenciales se desmoronan por el avance de la economía neoliberal. Así, la novela finiquita en forma dramática los cimientos de la modernidad occidental conectándose con variados postulados postmodernistas.

Palabras claves: Darío Oses, distopía, contaminación, paisaje, antipaisaje.

\section{ABSTRACT}

Darío Oses's novel 2010: Chile en llamas (1998) forecasts a future marked by the contamination of all spheres of society. We describe the story as distopic, since it is explained as a negative utopia that neutralizes the Earth's vital fluxes in connection with the human being. Landscapes, geographic and existentialist territories collapse by the advance of neoliberal economy. Hence, the foundations of western modernity

\footnotetext{
*Este artículo forma parte del Proyecto FONDECYT 1080338.
} 
are ended in a dramatic way. Furthermore, the novel is connected with several postmodernist categories.

Keywords: Darío Oses, dystopia, contamination, landscape, anti-landscape.

Recibido: 21-12-2009. Aceptado: 30-03-2010.

\section{ANTECEDENTES}

T as proyecciones que la escritura creativa manifiesta acerca de un porve_nir caótico y extremo, basadas siempre en una operación de intertextualidad con el contexto inmediato ${ }^{1}$, y una crítica tendiente a establecer los aspectos que conectan la literatura con la presencia de la naturaleza en un contexto desintegrado, nos permiten hoy indagar las posibles contingencias de un mundo narrativo distópico. Ya hemos avanzado ciertas ideas al analizar las traumáticas incorporaciones de territorios geográficos y existenciales devastados en la poesía chilena ${ }^{2}$. Por ejemplo, la visión adrede ecologista (o proto-ecologista) en "Oda a la erosión en la provincia de Malleco" (1956) de Pablo Neruda expresada en un lamento elegíaco por la pérdida de la capa germinal a causa de la deforestación y de las ambiciones que sobrelleva la agricultura de explotación. Por su parte, Nicanor Parra denuncia anticipadamente en sus "Ecopoemas" (1983) el carácter artificial del postmoderno, dando a conocer los vicios que éste incuba, la mala administración de la Tierra por parte de la humanidad, la polémica relegación del "tercer mundo" y su manejo como dispensador de materias primas.

En esta misma línea, nos ocupa ahora la narrativa chilena relacionada con la configuración actual de las sociedades y el impacto de la tecnología y la economía en el medioambiente. Uno de los ejemplos más claros de este discurso está contenido en 2010: Chile en llamas (1998) de Darío Oses. Después de su lectura nos resulta obvio que la novela de Oses tiene como antecedentes algunas obras anglosajonas de anticipación producidas durante la primera mitad del siglo XX. Por ejemplo, Brave new world (1932) de Aldous Huxley, que prefigura una sociedad vigilada en la que el proceso

${ }^{1}$ Desde la ecocrítica, otro tanto ha hecho el profesor Óscar Galindo (2004) en relación con la poesía de los chilenos Óscar Hahn y Gonzalo Millán. Por su parte, desde el análisis del subgénero ciencia-ficción, Macarena Aeco (2008) ha trabajado las nociones de espacios deformados del futuro como entrega de imágenes del presente.

${ }^{2}$ Véase Juan Araya, 2006 y 2008. 
reproductor pasa a manos de biólogos que controlan la cantidad y la calidad de las futuras generaciones. Tal sociedad descansa en la ciencia, la tecnología y la técnica, al extremo que los años son medidos en antes y después de Ford. Misma dirección la seguida por George Orwell en el relato 1984 (1949) que refiere una sociedad totalitaria y espiada por "la policía del pensamiento". El líder absoluto, el Gran Hermano, y el cuerpo policiaco acechan a cada individuo a través de pantallas vigilantes. Agreguemos a Ray Bradbury con Fahrenheit 451 (1953), donde se describe un sistema opresivo en el cual el libro es denostado y pasa a ser el principal enemigo público, pues hace notar a través de las ideas de los autores clásicos las diferencias intelectuales entre los hombres.

Por otra parte, en el ámbito del ensayo chileno se nos hace inevitable el parentesco de la novela de Oses con la obra del Dr. J. Valdés Cange, seudónimo de Alejandro Venegas (Melipilla 1871, Santiago 1922), autor del libro Sinceridad: Chile intimo en 1910. Leemos al crítico Ricardo Latcham:

[Alejandro Venegas] coincidiendo con el año del Centenario, de promisorios y optimistas contornos culturales, [...] plantea un problema típicamente enraizado en el ensayismo [...] al derivar los males del país de causas morales [...] Desde el punto de vista cultural inicia en la literatura chilena una corriente atrevida de interpretación, que han cultivado numerosos ensayistas contemporáneos [...Para Venegas el problema recae en el] aparato burocrático, la administración de justicia, la enseñanza pública, en todas sus ramas, y la privada en sus ángulos de egoísmo y de lucro, el ejército y la marina, el régimen criollo del turno del poder y el aprovechamiento del presupuesto fiscal, el alejamiento de las clases sociales, el atraso de la higiene hasta diezmar a los elementos más indefensos de la sociedad (Latcham, s/f).

Tanto Oses como Venegas, situados a las puertas de jubilosas proyecciones centenaristas, señalan los males morales, las apariencias y los simulacros de la sociedad chilena en un tono crítico y escéptico. En épocas diferentes, derriban el optimismo artificioso de políticos y ciudadanos en relación con aspiraciones "de redención social" irrealizadas y que siguen en compás de espera. Ambos, además, circunscriben sus perspectivas a las secuelas que dejaron experiencias políticas desgarradoras: a saber, la revolución o contrarrevolución de 1891, en tiempos de Balmaceda, y el golpe militar de 1973, en el gobierno de Allende.

La novela de Oses nos parece sencillamente audaz, pues mediante la fic- 
ción da otra vuelta de tuerca a la interpretación de la historia y la contemporaneidad del país. Ofrece una visión distópica del avance de la sociedad hacia un mal concebido y peor proyectado desarrollo, además de plasmar el fracaso de un destino colectivo en el marco de las corrientes de pensamiento modernas. Si "diezmar a los elementos más indefensos de la sociedad", como escribió Alejandro Venegas, es definirse por una política de supervivencia en la que los poderes económicos se intentan mantener inalterables en las mismas manos, en el 2010 de Oses es la tecnología, las comunicaciones, las privatizaciones, el fútbol y las drogas, las que proporcionan el control sobre un pueblo manipulado y sin voluntad.

\section{LA IRRUPCIÓN DE LA DISTOPÍA}

Usamos el término distopía desde la particular noción de "lugar malo". Distopía que significa llamar la atención "acerca de aquellas características negativas que apuntan ya en el presente hacia la deshumanización, la alienación, la degradación moral y la pérdida de valores, como la libertad y la dignidad" (Fernández Buey, 2007: 217). Si la utopía, el no lugar, alcanza su mayor desarrollo en el verosímil ensayístico con hombres como Moro, Bacon o Campanella, quienes reescribieron y actualizaron con el agitado espíritu renacentista un discurso cuyo origen se encuentra en la Grecia antigua, reactivando las virtudes expresadas en la concepción platónica del Estado, basadas en el amor, la armonía, la sabiduría y la justicia, la distopía novelada del siglo XX es la afirmación de un mundo en crisis: gobierno totalitario global (o desgobierno), anarquía institucional, corrupción política y administrativa, individualismo, segregación, neutralización de la subjetividad y la alteridad, contaminación ambiental, sociedad de control, tecnificación y desarrollo a gran escala de tecnología y ciencia al servicio de la economía y no del ser humano, represión y limitación de las libertades individuales y societarias, globalización, dominio absoluto de los massmedia, incomunicación, urbanocentrismo, elites invisibles e impalpables, fragmentación social política y cultural, mercenarismo, agotamiento de los bienes naturales (agua, combustible, tierras de cultivo), pérdida de la cultura letrada a causa de la implantación del soporte multimedial, tribalización y fanatismo, abolición de la democracia, manipulación genética del hombre, entre otras.

Tanto el no lugar, la utopía, como el lugar malo por venir, la distopía, son producto de una escritura transitiva, vale decir un modo de intervenir la realidad desde una postura de análisis de los rasgos negativos, tóxicos y des- 
tructivos del presente, que asfixiarían el futuro: exposición de los elementos del hoy que perturban el desarrollo coherente, conexo de las sociedades o comunidades ordenadas por el principio rector de un gobierno legítimo. Su código, en síntesis, es la hipertrofia de la perversión social. En la distopía novelada es fácil advertir la reflexión filosófica, ético-moral, cultural y política, que arremete contra regímenes totalitarios y/o fundamentalistas. En la novela de Oses se observa este rasgo desde un ángulo paradójico, ya que el neoliberalismo extremista engendra una nueva forma de absolutismo cuya instancia última es el libertinaje.

Desde las claves de la ecocrítica, lo que da a conocer un relato distópico no es otra cosa que un texto que revela un estado de crisis que encuentra su explicación

en cierta determinación secular del pensamiento según la cual entre hombre y naturaleza existiría una brecha cualitativa que los distancia pese a toda su cercanía, un salto diferencial, fundamentado en la primacía y la sobrevaloración de su propia racionalidad, que deja abolida cualquier posibilidad de pensar en una mutua pertenencia entre ambos y justifica la condición de señorío en que se autoinstala el primero, a partir de su poderío racional y técnico, sometiendo a una desmedrada situación de vasallaje a la segunda; en cuanto ella queda dispuesta como objeto de su conocimiento y a la postre de su manipulación. Es decir, como si fuera una "gigantesca estación de servicio" -en palabras de Heidegger-, a la cual se puede y se debe incluso recurrir en busca de "subsistencias", de verdaderos stocks de bienes consumibles, hasta el límite en que su alteridad se aproxima peligrosamente al punto de la implosión (Villarroel, 2006: 184).

La novela de Darío Oses se conecta con variados postulados postmodernistas. En lo que nos interesa, limitamos nuestra mirada a la reflexión de Fredric Jameson acerca de la cultura contemporánea y su modo de intervención en "la Naturaleza", desde una concepción filosófica de oikos, de procedencia heideggeriana. El fragmento posee un potente sentido gráfico y nos direcciona violentamente a observar el divorcio entre hombre y ambiente:

Hoy en día, sin embargo, en el momento del eclipse radical de la propia naturaleza, resulta posible reflexionar sobre el asunto de modo diferente; después de todo, el "camino campestre" de Heidegger ha sido irremediable e irrevocablemente destruido por el capitalismo tardío, por la revolución verde, por el neocolonialismo y la megalópolis, que construye sus superca- 
rreteras sobre los antiguos campos y solares vacíos y convierte la "casa del ser" de Heidegger en condominios, o en edificios paupérrimos, infestados de ratas y carentes de calefacción. En ese sentido, el otro de nuestra sociedad ya no es la Naturaleza, como lo era en las sociedades precapitalistas, sino algo distinto que tenemos que identificar (Jameson, 1991: 59, nuestro énfasis).

Es así como en $2010 \ldots$ accedemos a la ficcional versión chilena del fin de la historia. Oses liquida los puntos de referencia de la última modernidad: describe un gobierno central inoperante; un congreso farandulero, que por extensión abarca la elite política mundial en su totalidad, sociedad del espectáculo; extremismo político-económico con ultraliberales en el poder, conservadores al estilo colonial y patriarcal y una izquierda aniquilada, compuesta por pequeños grupos o células clandestinas, o en su defecto, inserta secretamente en tribus y pandillas que luchan entre sí en gigantescas ciudades; una legalidad inexistente; anarquía social; permisivismo total en materia de drogas, sexo y brujería; abolición del estado y de sus instituciones, incluyendo al ejército y la policía; servicios de seguridad que brindan sólo protección a empresas y magnates, funcionando como mercenarios, etc. Asimismo, desaparecen las relaciones personales, incluido el sexo, y cualquier forma de organización a gran escala: política, social, económica, cultural, histórica. En la práctica, la única actividad humana que provee de la hoy por hoy tan mentada "unidad nacional" es el fútbol. No obstante, este deporte resulta de igual manera un mecanismo de vigilancia del poder: hace olvidarse al pueblo de su miseria, a la vez que lo descontrola y hace exhibir su cara más bárbara al provocar ataques xenófobos en contra de pueblos hermanos.

\section{BASURA Y DISTOPÍA: EL VELO TÓXICO}

A este estado de cosas calamitoso, Oses incorpora en el relato la metáfora de la basura. Ésta se propaga por el texto como la representación más patente de la situación en que se encuentra el país y el planeta por extensión. Entroncando de manera irónica con el contexto bicentenarista el Regimiento Ceremonial Patria Nueva, el único destacamento que logró pervivir del antiguo ejército, se encuentra en sus narices con la desagradable presencia de la suciedad. En la elipse del Parque O'Higgins, en el que ensayarán el desfile preparatorio de conmemoración de la fecha que señala el bicentenario, hieden numerosos bloques de basura compactada: 
El Regimiento había llegado a la elipse en los destartalados buses que podía pagar con su presupuesto. En cuanto bajaron, los hombres percibieron el hedor y luego vieron la pista obstruida por montones de bloques de basura compactada. Se desplegaron por el desierto de asfalto y pasto seco, en busca de alguien que pudiera responder por esa afrenta. Llegaron hasta las ruinas de un parque de juegos, donde los gigantescos cadáveres horadados de tribilines y mikeys [sic] reposaban entre las estructuras herrumbrosas de una montaña rusa. Al fin, entre unas casetas que alguna vez debieron ser baños o camarines, encontraron la oscura vivienda del administrador.

Este se asomó verdoso y sin afeitar. Se negó a ir a comprobar personalmente la existencia de los cubos de desperdicio.

-No es la primera vez que pasa. ¿Qué quieren que haga? -rezongó-. Los piratas se dejar caer de noche. Descargan toda esa mierda en un minuto y desaparecen. Yo aquí no tengo personal de vigilancia ni menos de limpieza $[\ldots]$

${ }_{-}^{-}$Exijo que retire inmediatamente esas inmundicias de la pista!- gritó el coronel. Como única respuesta, la puerta de la húmeda casucha se cerró en sus narices $[\ldots]$

- No voy a poner a mis hombres a limpiar esta mugre -dictaminó el coronel-. Que las autoridades la vean y la huelan. ¡Que se den cuenta de una vez por todas del estado en que está el país! (Oses, 1998: 16-17).

La paradoja induce a pensar que si los militares abrieron el camino del neoliberalismo, lo abrieron también a la basura acumulada debido a los excesos de aplicación de la teoría económica de Friedman. Son ellos ahora quienes, simbólicamente, vestidos con uniformes impecables y de gala, se hunden en el vertedero en que se ha convertido el escenario principal donde durante años se ha celebrado la Parada Militar de las Fiestas Patrias. Recordemos que ese lugar que hoy conocemos como Parque O'Higgins (ex Parque Cousiño, fundado en 1873) fue un exclusivo recinto de la aristocracia chilena durante parte del siglo XIX y la aspiración del intendente Benjamín Vicuña Mackenna de dotar a Santiago de pulmones verdes. Después se convirtió en espacio destinado a ramadas, fondas y fiestas populares. En 1972, bajo la presidencia de Salvador Allende, fue redenominado Parque O’Higgins.

Si Vicuña Mackenna ideó pulmones verdes para oxigenar Santiago, proponiendo audaces medidas, de las cuales sólo algunas fueron llevadas a cabo, Oses crea un "mundo en descomposición". Este orbe enrarecido, azotado por los rayos ultravioleta, la polución del aire y de la permanente lluvia 
radioactiva y ácida, obliga a los habitantes a usar gafas y mascarillas como acto cotidiano. Por lo tanto, no es posible percibir en el texto una celebración óptima en un medio absolutamente contaminado, degradado, en el cual todo se desdibuja. Esta celebración carece de elementos puros de la realidad, pues no sólo hay carencia de formas, sino que también de contenido, como lo enuncia el narrador al referirse al desgobierno imperante, al fanatismo y a la farandulización de los políticos. Entonces, la visión distópica de Chile choca violentamente con la utopía que construyeron algunos de nuestros tribunos e intelectuales del pasado: "Ahora la patria se estaba esfumando como un espejismo. Ya no quedaban parrones ni paisajes familiares, ni trenes nocturnos, ni rincones amables. La derrota arrastraba hacia el resumidero los sueños, los amigos, la casa del abuelo, los recuerdos de los días de colegio" (Oses, 1998: 47). Este estado de cosas disemina hasta el concepto de Estado-nación: "Aunque no lo declararan abiertamente, muchos ultraliberales tenían el íntimo convencimiento de que la nación era un concepto decimonónico, que ya no tenía ninguna utilidad puesto que los negocios se hacían ahora en grandes espacios transnacionales" (Oses, 1998: 30).

Un solitario, errático y deteriorado dirigible suspendido en el cielo santiaguino del año 2010, que sirvió, al igual que otros, de propaganda comercial para incitar a los habitantes de la ciudad a huir de ella y habitar parcelas de agrado, da a conocer el escenario espantoso de la epónima celebración del bicentenario. A la par, sintetiza la catástrofe ecológica a la que se ha llegado como consecuencia de la explotación y de la libertad de comercio, de la ausencia de ética ciudadana y corporativa, en la que el proyecto país se desvanece y queda convertido en ruinas. Los dirigibles, último recurso propagandístico para promover una vida fuera de las ciudades, sitiadas por sus propios miedos, a la manera de paraísos habitables, quedaron

abandonados y subieron al cielo hasta hincharse y reventar, o quedaron a merced del viento que los estrelló contra antenas y edificios altos. Trozos de carteles de lona que mostraban familias sonrientes entre árboles, prados y otras escenas de dicha residencial, cayeron del cielo como el ofrecimiento ya caduco de una forma de vida distinta para esa ciudad que no sabía qué hacer con sus desperdicios, con sus hordas de jóvenes iracundos, con sus interminables filas de autos viejos y mal carburados, ni con su propia violencia (Oses, 1998: 35-36).

Tal es el escenario de la devastación. Paradójicamente, algunos de aquellos hombres que facilitaron la implantación del modelo en las décadas de 
los 80’ y 90', en el año 2010 de Oses figuran como sus más acérrimos y enconados enemigos. En efecto, el senador Juan Antonio Eyzaguirre, personaje desalentado por la política extrema de sus antiguos aliados, renuncia a su cargo y se retira de la vida pública para recluirse en su fundo del valle central. Compra los terrenos aledaños y reconstruye la típica hacienda de los siglos XVII al XIX. El ex senador emite llamados en medios escritos dirigidos a la ciudadanía para "huir de la incertidumbre y degradación de las ciudades", a un lugar "donde encontrarían la protección física y espiritual que sólo podría brindarles una gran familia" (1998: 110). Este reducto es denominado Hacienda Corazón de Jesús. Allí el político conservador pretende restaurar "la hacienda chilena" como "el núcleo ordenador de la sociabilidad de este país". Por eso, piensa, "hay que volver a ella si se quiere reconstruir el orden destrozado por la orgía de impulsos inmorales y anárquicos y por el desquiciamiento total que ha traído el liberalismo".

Así, plantea dar "el primer paso de un proyecto para ruralizar a Chile y ponerlo en el buen camino que perdió al encandilarse con la modernidad" (112). Estamos claramente ante un proyecto utópico calificado por los liberales como "un experimento reñido con la más elemental racionalidad económica" (111). Este "regreso a los orígenes", a los antepasados, parte de la base de que en el periodo colonial-patriarcal existió un equilibrio social, pues se vivía en forma "armónica" entre patrones, administradores, curas, capataces, peones e inquilinos: "una sana jerarquía”, en términos de Eyzaguirre. "La única solución para el país era volver a la tierra y regenerarse en el cultivo de ella", remata. Sin embargo, como sabemos, esta utopía interna es reaccionaria ya que se legitima desde un supuesto falso: nunca existió una "sana jerarquía" en las haciendas, sino más bien un régimen feudal, de propiedad privada y de explotación brutal, primero de forma rudimentaria y en seguida, de la mano de la ciencia, la mecánica, la técnica y la tecnología, lo que, a la postre, permitió la depredación, la producción irracional y el consumo a gran escala, agotando las tierras fértiles y descuidando las tierras poco aptas para la siembra.

Es de notar, además, que la idea del desarrollo sustentable también ha sido desechada completamente por ser considerada una quimera. El territorio, incluido playas y mares, ha sido asolado y el Océano Pacífico convertido en un mar muerto:

la línea de la costa con sus gigantescas instalaciones portuarias, que ahora atendían las necesidades de carga de los países vecinos y las estructuras herrumbrosas de los barcos factoría que succionaron a todos los organis- 
mos comestibles hasta dejar el mar definitivamente muerto. En fin, todo lo que podía venderse había sido exportado. Superada ya la etapa de la producción sustentada en recursos naturales, el país seguía prosperando (Oses, 1998: 36).

Aquellos opositores a la depredación, según el relato, "un grupo de economistas, coludidos con el ecologismo, que insistían en pasar la cuenta por la destrucción del medioambiente", albergados en la Universidad de Chile, "fueron eliminados con la aplicación de diversas medidas, destinadas a que no sobreviviera ni la sombra de tales proyectos que atentaran contra los intereses del mercado". Habiendo desmalezado el camino, el capitalismo transnacional desbarata, fragmenta y destruye el alma mater del país, convirtiéndola en un eslabón más del sistema económico:

un inversionista colombiano compró las ingenierías para hacer un politécnico por donde circularían alumnos y dólares de toda Iberoamérica. Una Isapre, asociada con un consorcio farmacéutico, compró las facultades del área de las ciencias médicas y biológicas, para disponer de profesionales y laboratorios baratos. En seguida lanzó al mercado un programa económico de salud en que toda la atención la prestaban estudiantes en práctica. El dueño de los supermercados Kalidad compró las carreras de Derecho, Economía y Ciencias políticas. Organizó con ellas un revolucionario sistema de educación a distancia. La matrícula y la inscripción de cursos podía hacerse en cualquiera de los locales de la cadena Kalidad, en boxes contiguos a los que expendían pollos asados o boletos de lotería. Por la compra de productos, por un determinado valor, se hacían descuentos en los pagos de los aranceles. Las humanidades y las artes no tuvieron interesados, de modo que fueron clausuradas y sus locales salieron a remate (Oses, 1998: 120-121).

Así, las privatizaciones cubren todos los servicios del país, inclusive, como vimos, el ejército:

Fue poco después que se consumó la privatización de la defensa. Los argumentos técnicos indicaban que no había otra solución [...] Un implacable informe económico señaló que era urgente modernizar el ejército, que una inversión inicial en vigilancia satelital de fronteras, sistemas balísticos automatizados y otros adelantos tecnológicos, produciría importantes ahorros en personal. Agregaba que parte no despreciable del tiempo laboral de 
un militar se destinaba a desfiles y rituales, no relacionados directamente con la defensa, o al estudio de historia militar, estrategia clásica y otras materias, que con los avances técnicos habían quedado obsoletas. Recomendaba, por lo tanto, crear un pequeño regimiento, que se encargara de todos los ritos y ceremoniales, y una corporación privada que asumiera las funciones profesionales de la defensa (Oses, 1998: 29-30).

Todo esto sucede mientras "el General" es mantenido con vida artificialmente. Si éste pretendió que el ejército tuviera un desarrollo acorde con las funciones que el mismo le había asignado tras el golpe de Estado, su proyecto concluye en el mayor de los fracasos. El ejército se convierte en sociedad anónima: "al final terminó por constituirse la Corporación Cóndor de Servicios de Defensa S.A.” (31). Desde el punto de vista de la novela, la idea rectora de "reconstrucción nacional", piedra angular de la política castrense desde 1973, fue aplicada sin reflexionar acerca de las consecuencias que apuntarían a la desmembración del cuerpo cívico y del espíritu del país.

Podríamos concluir realizando una transposición de las ideas de Oses al contexto que ya han descrito los tratadistas, entre ellos el brasileño Leonardo Boff, quien nos dice que

el paradigma de la modernidad occidental, hoy globalizado, ha entrado en crisis por agotamiento propio y por efecto de la implosión. Es semejante a un árbol que ha llegado a su clímax y entonces cae fatalmente por haber agotado su energía vital. Así, digamos su nombre, el capitalismo ha alcanzado su fin en un doble sentido: fin como realización de sus virtualidades y fin como término final y muerte (Boff, 2009).

\section{DEVASTACIÓN ECOLÓGICA. REPRESENTACIÓN DE UN ANTIPAISAJE}

La observación de la naturaleza, sentida desde los ojos del ser humano y filtrada por las directrices fijadas por el tamiz cultural peculiar de cada sociedad, permite tener una percepción del paisaje. En éste se refleja la disposición valorativa e instrumental del hombre frente a la gran alteridad que es la Naturaleza. El hecho de construir la visión modelo de un paisaje es una manera de entender las relaciones ecológicas y una forma de producción cultural. Persuadidos por la atinada síntesis del profesor del Departamento 
de Filosofía de la Universidad de Chile Raúl Villarroel, adherimos al siguiente pensamiento:

la cosmovisión predominante en el mundo occidental, previa a la revolución científica de los siglos XVI y XVII, era la de un mundo unitario, en que el ser humano experimentaba pertenencia y correspondencia esencial con su entorno, participando directamente en el devenir sin que ello le resultara ajeno o extraño. Su destino personal se encontraba indisolublemente ligado al de la totalidad del universo en medio del cual su existencia cobraba pleno sentido; su identificación con el ambiente tenía un máximo significado (Villarroel, 2006: 184).

Así, las formas de decir un paisaje se insertan en el imaginario de un país y constituyen su fuente nutricia y su rostro. No obstante, y en aras de la industrialización y la economía de desarrollo la humanidad produce transformaciones en su entorno, tal como ocurre en el oscuro horizonte imaginado por Oses. En la novela la continuidad del paisaje, la continuidad del rostro, empieza a desvanecerse y en su lugar emerge un antipaisaje (una acuarela urbana devastada como representación de la distopía), es decir, el paisaje que no quisiéramos nunca:

en el país todas las cosas iban perdiendo su forma y sus contornos. Aun los edificios de concreto parecían de plástico calentados por los rayos del sol invisible que penetraban a través de la bruma. Y era esta bruma húmeda y tórrida, hecha por una mezcla de emisiones de gases y nieblas, provocadas por las alteraciones climáticas, el material que se veía más estable y consistente en la ciudad de Santiago, en la primavera del 2010 (Oses, 1998: 8).

Del mismo modo, una de las características más sobresalientes del paisaje de la nación, la Cordillera de los Andes, sello material de identidad, se borronea enteramente: "El aire espeso diluía los perfiles de la cordillera y de los megaedificios que albergaban a los grandes centros de negocios" (8). Sobrevolando la tóxica espesura del aire de la ciudad de Santiago, el dirigible sin control (un derrotado e inútil espectador a la deriva que actúa como el anverso del panoptismo del capital) es el único y mudo testigo del calamitoso antipaisaje que ofrece Chile en el mayor cordón montañoso del continente:

Si [el dirigible] hubiese tenido ojos podría haber contemplado desde arriba 
la cordillera como un cadáver seco y vaciado de sus venas minerales. Y la vieja piel erosionada de los montes, donde sólo quedaban las raíces de los árboles hechas astillas y embarcados al oriente, y la tierra que cerraba sus muslos estriados en torno a los escasos cursos de agua en los que persistían manchas verdes de zarzas enredadas con matorrales de kiwis salvajes (Oses, 1998: 36).

La extracción intensiva de minerales, el trastorno y la utilización desmedida del curso de las aguas andinas, el cambio climático y la radiación ultravioleta han convertido gran parte de la cordillera en un páramo erosionado, seco y sin vida. A la par, el alto nivel de radiación procedente del sol causa en hombres y animales afecciones oculares y dérmicas. Los hombres del Regimiento Patria Nueva obligatoriamente deben utilizar antiparras especiales para protegerse de los rayos UV. Las gafas, en una lectura sublineal, legitiman y enfatizan el individualismo implantado por el sistema:

Desde el día anterior se venía advirtiendo que el agujero del ozono que se contorsionaba allá arriba, cambiando de posición y de forma, estaba sobre Santiago. Si la radiación UV fuera visible, los soldados hubieran podido contemplarla como una torrencial lluvia tornasolada, que rebotaba en el paraguas del coronel, para escurrir por las graderías y saturar la pista como una liviana inundación suspendida sobre el pavimento.

No era recomendable permanecer mucho tiempo a la intemperie. Aun así, los muchachos, con los rostros untados con cremas bloqueadoras, seguían marchando tras el brioso tambor mayor y mantenían en alto sus estandartes y pendones que el viento letal atacaba y desteñía [...]

Abajo, en la ciudad sombría, un predicador callejero levantó histriónicamente los ojos y se quitó las gafas desafiando la lluvia de radiación ultravioleta. Tenía intenciones de decir: “¡Atrévanse a mirar hacia lo alto! ¡Volvamos a tener confianza en el cielo!" pero al ver el dirigible en movimiento se quedó mudo y sólo se limitó a señalar con el índice ese pequeño milagro a su audiencia [...]

Nadie recordaba desde cuándo se encontraba el dirigible anclado en el aire. Los días más oscuros parecían una condensación del smog. Cuando algún rayo de sol se abría paso entre las espesas emanaciones de la ciudad, se hacía visible la textura escamosa de la tela engomada, donde se habían desteñido hasta hacerse ininteligibles los rótulos publicitarios [...]

Pero la mayor parte de los días el dirigible no era más que una silueta borrosa, como el sol y la luna, invisible para los habitantes de Santiago que 
no despegaban los ojos del suelo para evitar la radiación que provocaba epidemias de cataratas y otras afecciones oftálmicas[...]

La vida, después de todo, no era tan difícil. La radiación daba un excelente pretexto para encerrarse de los ojos hacia dentro. Hombres y mujeres nunca se quitaban las gafas y así eludían el encuentro con los ojos apagados de los otros (Oses, 1998: 19-37).

En este contexto distópico, los cambios en la configuración de los territorios y modos de vida, cambios climáticos y calentamiento global, el nomadismo y las "intervenciones humanitarias", según intereses económicos transnacionales en las más diversas e inexploradas zonas del globo, permiten la proliferación de peligrosos virus que causan pánico en los habitantes de las ciudades, quienes evitan cualquier contacto interpersonal:

[El alférez] había concurrido con otros hombres del Regimiento Patria Nueva a visitar al general, que yacía aislado del aire donde acechaban virus y bacterias llegados de todo el mundo al Hospital de la Caja de Previsión de la Defensa, más conocido como el Hospital del Legionario.

El inmenso edificio estaba siendo demolido por secciones y se defendía infectando a las cuadrillas de obreros con los virus que le habían llevado los soldados que lucharon en emiratos árabes, en estados separatistas de Europa Oriental, en Centroamérica o en países africanos, donde se reactivaban intermitentemente milenarias reyertas tribales (Oses, 1998: 24-25).

Resulta obvio que la relación de la humanidad con la naturaleza, en el texto de Oses, ha llegado al punto límite de tensión, no sólo por las contaminaciones de toda índole, sino por el agotamiento de las energías vitales que podrían exigir una salida. Félix Guattari en Las tres ecologías postula que se ha aceptado como natural una evolución negativa o involución "debido al hecho de un desconocimiento y de una pasividad fatalista de los individuos y de los poderes respecto a estas cuestiones consideradas en su conjunto" (1998: 31).

El recientemente citado Raúl Villarroel escribe sobre la disolución del vínculo entre el destino personal con la totalidad del universo, en la medida que la revolución tecnocientífica se extiende a todas las esferas de la vida. Es importante señalar que aquí no se reivindica la idea de corte radical con el progreso; por el contrario, se pretende advertir sobre las consecuencias de la "desterritorialización salvaje" y de la estandarización de los pueblos y los espacios en que ellos habitan. "Hoy menos que nunca puede separarse 
la naturaleza de la cultura, y hay que aprender a pensar "transversalmente" las interacciones entre ecosistemas, mecanósfera y Universo de referencias sociales e individuales", apunta Guattari. Cada uno de estos cortes que hemos heredado forma parte de un solo flujo vital: todo está conectado con todo, según la primera ley de la ecología. En ese entendimiento repercute negativamente cualquier acción insustentable en algún punto.

Boff, en concordancia con la línea de pensamiento expuesta, se refiere a las deudas que inciden en las cuatro principales vertientes de la preocupación ecológica: 1) la deuda ecológico-ambiental, ocasionada por la insuficiente calidad de vida de nuestra sociedad, 2) la deuda ecológico-social, ocasionada por la injusticia social, 3) la deuda ecológico-mental, ocasionada por el excesivo antropocentrismo que se ha adueñado de nuestra mente y 4 ) la deuda ecológico-integral, ocasionada por la fragmentación de los saberes (2005: 70-71).

Consideramos que Oses en su desarrollo novelístico toma en cuenta estas deudas para establecer su distopía del bicentenario de Chile. La destrucción del medioambiente, la neutralización del ser político del pueblo y su descarrío, el ordenamiento elitista de la sociedad de acuerdo con una brutal teoría económica y la fragmentación de la realidad en mil pedazos, olvidando que cada uno de ellos forma parte de un todo, obligan a pensar en cómo contrarrestar la evolución negativa, la cual afortunadamente aún no tiene su total concreción en la realidad, pero que en la literatura cumple el papel de sacudirnos y pensar en torno al aniquilamiento progresivo de los lazos y energías vitales.

El hombre, a partir de una realidad ominosa, deberá reinstalarse en la Tierra.

\section{REFERENCIAS}

Aeco, Macarena. 2008. "Ciudad, espacio y ciberespacio en la ciencia-ficción chilena reciente: Tres versiones del laberinto", en Acta Literaria 37, pp. 25-42.

Araya, Juan. 2006. "Ética, política y poética: hacia una lectura ecocrítica de Pablo Neruda", en RCLL 63-64, pp. 253-263.

Araya, Juan. 2008. "Nicanor Parra. De la Antipoiesis a la Ecopoiesis", en Estudios Filológicos 43, pp. 9-18.

Boff, Leonardo. 2009. "La filosofía puede ayudarnos". Servicios en Comunicación Intercultural Servindi. [En línea] Disponible en: http://www. servindi.org/actualidad/opinion/8327. [Consulta: 03/04/2010]. 
2005. Florecer en el yermo: de la crisis de la civilización a una revolución radicalmente humana. Santander: Sal Térrea.

Bradbury, Ray. 1968 [1953]. Fahrenheit 451. Buenos Aires: Minotauro.

Fernández Buey, Francisco. 2007. Utopías e ilusiones naturales. Barcelona: El viejo topo.

Fundación de Estudios Económicos. 1976. Chile 2010: una utopía posible. Santiago: Universitaria.

Galindo, Óscar. 2004. “Distopía y apocalipsis en la poesía de Óscar Hahn y Gonzalo Millán”. Anales de Literatura Hispanoamericana 33, pp. 65-76.

Guattari, Félix. 1998. Las tres ecologías. Valencia: Pre-Textos.

Huxley, Aldous. 1999 [1932]. Un mundo feliz. Madrid: El Mundo.

Jameson, Fredric. 1991. Ensayos sobre el postmodernismo (compilación de Horacio Tarcus). Buenos Aires: Imago Mundi.

Latcham, Ricardo. S/f. "El ensayo en Chile en el siglo XX". [En línea]. Disponible en: http://mazinger.sisib.uchile.cl/repositorio/lb/uchile/desarrollochile02/parte03/01.html. [Consulta: 03/04/2010].

Neruda, Pablo. 1956. Obras completas. Buenos Aires: Losada.

Orwell, George. 1997 [1949]. 1984. Barcelona: Destino.

Oses, Darío. 1998. 2010: Chile en llamas. Santiago: Planeta.

Parra, Nicanor. 1983. Poesía política. Santiago: Bruguera.

Valdés Cange, Dr. J. (Alejandro Venegas). 1998. Sinceridad: Chile intimo en 1910. Santiago: CESOC.

Villarroel, Raúl. 2006. La naturaleza como texto: Hermenéutica y crisis ambiental. Santiago: Universitaria. 